\title{
APPLICATION RO TECHNIQUES WITH "OPEN CHANNEL" MEMBRANES TO TREAT WASTEWATER FOR RECYCLING AND REUSE: MODERN METHODS OF ENVIRONMENTAL PROTECTION AND WATER RESOURCES MANAGEMENT
}

\author{
Nikita Matveev, PhD Student \\ The Moscow State University of Civil Engineering, \\ Moscow, Russia \\ H. Alm \\ SWECO Environment, \\ Sweden
}

\begin{abstract}
The solution to contemporary ecological problems such as wastewater reuse requires rational water resources management, and in turn, rational water resources management requires the development of new, more efficient techniques. The modern concept of rational water resources management requires the development of new efficient techniques that provide wastewater treatment and reuse. For many local industries, the problem of wastewater treatment and discharge into surface reservoirs can't be solved through the use of conventional biological treatment techniques. Current discharge standards require very strict removal of a number of impurities such as ammonia, nitrates, phosphate, etc. To reach this level of removal, expensive reagents and sorbents are used. As RO membranes simultaneously reject all dissolved impurities such as BOD, TDS, ammonia, phosphates etc., they become very attractive for the direct treatment of wastewater without biological stage. To treat wastewater, specially designed membrane "open channel" modules are used that do not possess "dead areas" that cause fouling or require pretreatment. A solution to the concentrate disposal problem is presented that consists of reducing of initial wastewater volume by 100 times. Concentrate is withdrawn from membrane unit as sludge humidity. Local utilities and privately-held industrial sites are encouraged to reuse wastewater and reduce freshwater intake, thereby prompting rational water management and reducing environmental pollution.
\end{abstract}

\section{KEYWORDS}

Reverse osmosis, stormwater treatment, open-channel module, wastewater reuse, ecology.

\section{INTRODUCTION}

Protection of water resources from pollution is considered to be an important ecological problem that becomes more and more complicated with urban growth and development of industrial and 
agricultural water consumption. The use of different chemicals for industrial, agricultural and domestic purposes tend to constant degradation of water quality, accumulation of detergents, oil products as well as biological nutrients. Rational use of water resources to reduce their contamination should be introduced into practice as well as measures should be undertaken to transform sewage into a new source of raw water that could be used by communities for agricultural and technical purposes. To improve quality of wastewater new techniques that should be developed as conventional water treatment methods (coagulation, filtration, sorption, bioreactor etc.) do little to efficiently remove dissolved contaminants and maintain operational costs within reasonable limits.

Many EU countries are beginning to pay attention to water management and reuse. For example, in Sweden, harvesting rainwater to distribute water over the year is not common. However, it is common to use storm water management to add values in the urban environment, in example irrigation of urban greenery and parks. Public greenery is also used "multifunctional" areas. Multifunctionality in this context refers to the integration and interaction of different functions or activities on the same piece of land - like allowing a public playground to be flooded during heavy rains. Furthermore a major focus, in Sweden, has for decades been to managing stormwater locally where it occurs, usually through infiltration and percolation in the first place and secondly detention.

Legal requirements are often based on a pollution perspective. With the introduction of the European Water Framework Directive, it has become common with demands like the pollution load on recipients should not increase on an annual basis. This is often calculated using standard concentration per land use.

Modern membrane techniques (UF, NF, RO) have demonstrated high efficiency in removal of suspended matter, bacterial, as well as organic and mineral ingredients. Meanwhile, certain problems of membrane fouling arise, resulting in shortening of membrane life and reductions in product flow. To prevent formation of fouling layers on membrane surfaces and cake resistance increases, a number of measures are applied, such as backflushes, chemical cleanings, feed pretreatment. Despite these measures, fouling remains a major factor that determines operational costs.

Long operational experience of membrane units to treat natural water as well as theoretical and experimental investigation results enable us to draw to a conclusion that hydraulic, hydrodynamic and chemical processes that occur during membrane separation are closely connected. Many researchers approve of this concept in a number of reports [1] but nevertheless many state-of-the art reviews demonstrate conventional limited description of these processes without relationship. Meanwhile, critical and detailed assessment of different processes separately shows the importance and significance of each process in formation of the whole overview of membrane fouling and deterioration of membrane performance characteristics.

Natural surface water contains high concentrations of suspended and colloidal matter with different particle size distribution, as well as dissolved organics (mainly humus substances) with various molecular weights. Membrane fouling mechanisms caused by different foulants (sparingly soluble compounds, bacterial, organic and colloidal matter) are different. Suspended and colloidal particles deposit and adhere on membrane surface thus building fouling layer that create hydraulic resistance and reduce product flow. Organic compounds adsorb on membrane surface and on deposits of particles. 
For a long time formation of colloidal fouling layers was attributed to hydrodynamic flow characteristics (such as cross-flow velocities, concentration polarization level, product flow etc.) and membrane sorption and adhesive properties were totally ignored. Meanwhile, research has revealed that membrane surface characteristics (surface charge, hydrophilic properties that are depended on polymer composition) could have become decisive factors when biofouling, colloidal and organic fouling occurs. This conclusion prompted a new direction of membrane research development of low-fouling membranes and modification of membrane surface to reduce fouling.

It was also reported that configuration of membrane channel and module also should be considered as decisive factor that influence fouling [1,2]. Spiral wound configuration is widely applied at more than $90 \%$ of all water installations but nevertheless is considered as useless to treat surface water that contain suspended and organic matter due to fouling hazard. At the present time ultrafiltration is considered as the best pretreatment tool for RO facilities where tubular and capillary UF membranes are utilized. These membrane configurations are supposed to demonstrate better reliability than spiral wound flat sheet channel due to lower delta pressure values, better conditions for hydraulic flushing and backwashing performance. Besides, tubular and capillary membrane channels, as well as plate and frame and flat sheet elements channels are still very expensive that makes RO pretreatment costs higher than RO itself.

Different innovations were implemented and tested throughout the research program performed. Various types of spacers, as well of double spacers were tried and tested. To eliminate dead areas and provide low flow resistance, a spacer should not touch membrane surface. One of the best solutions was the idea of "separate" spacer where mesh fibers are glued to membrane surface. RO module spacer is a platted mesh where parallel groups of fibers are crossed and welded forming a rhombic structure (see Figure 1).

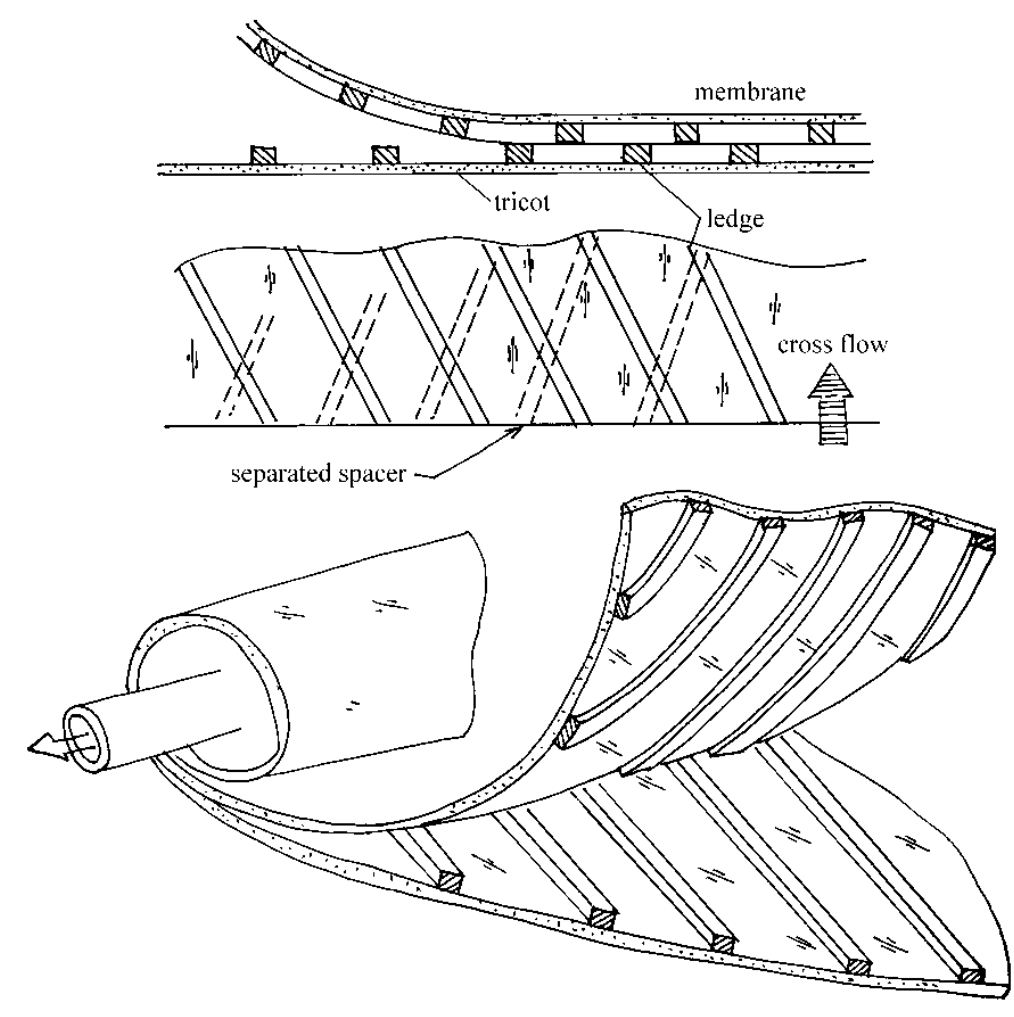

Figure 1. Spiral wound module with open-channel configuration. 
In our construction parallel groups of fibers (ledges) are glued to membrane surface whereby ledges on opposite sides are oriented in different directions. The glued fibers form a rhombus having $1.2 \mathrm{~mm}$ width and $0.35 \mathrm{~mm}$ thickness. When a module is rolled, opposite membrane sides are pressed to each other but ledges separate membrane surfaces providing enough space for flow with very low resistance. The idea of a channel configuration was already patented and some innovations are being continuously introduced. Several modules of 1812 standard were rolled using various types of NF and low pressure RO membranes (cellulose acetate, TFC based on polyvinyl alcohol and polyamide). Cellulose acetate asymmetric NF membranes were provided by Vladipore Co (Vladimir, Russia) and TFC RO membranes were ESPA samples (Hydranautics).

\section{DEVELOPED R.O. TECHNIQUES}

At early stages of wastewater treatment with the use of membranes, the role of the membrane was limited to "supporting" conventional biological treatment by reducing suspended matter and activated sludge, and to post-treating biologically treated wastewater.

Biological water treatment does not always ensure high quality of purified water to efficiently reuse it for technical and domestic purposes. To provide efficient reduction of TDS, organics, nitrates, phosphates etc. reverse osmosis desalination techniques are be being implemented to post treat wastewater after biological treatment. As RO feedwater should be adequately pretreated to escape membrane fouling and scaling, the use of membrane bioreactor facilities is required to treat wastewater (see Figure 2).

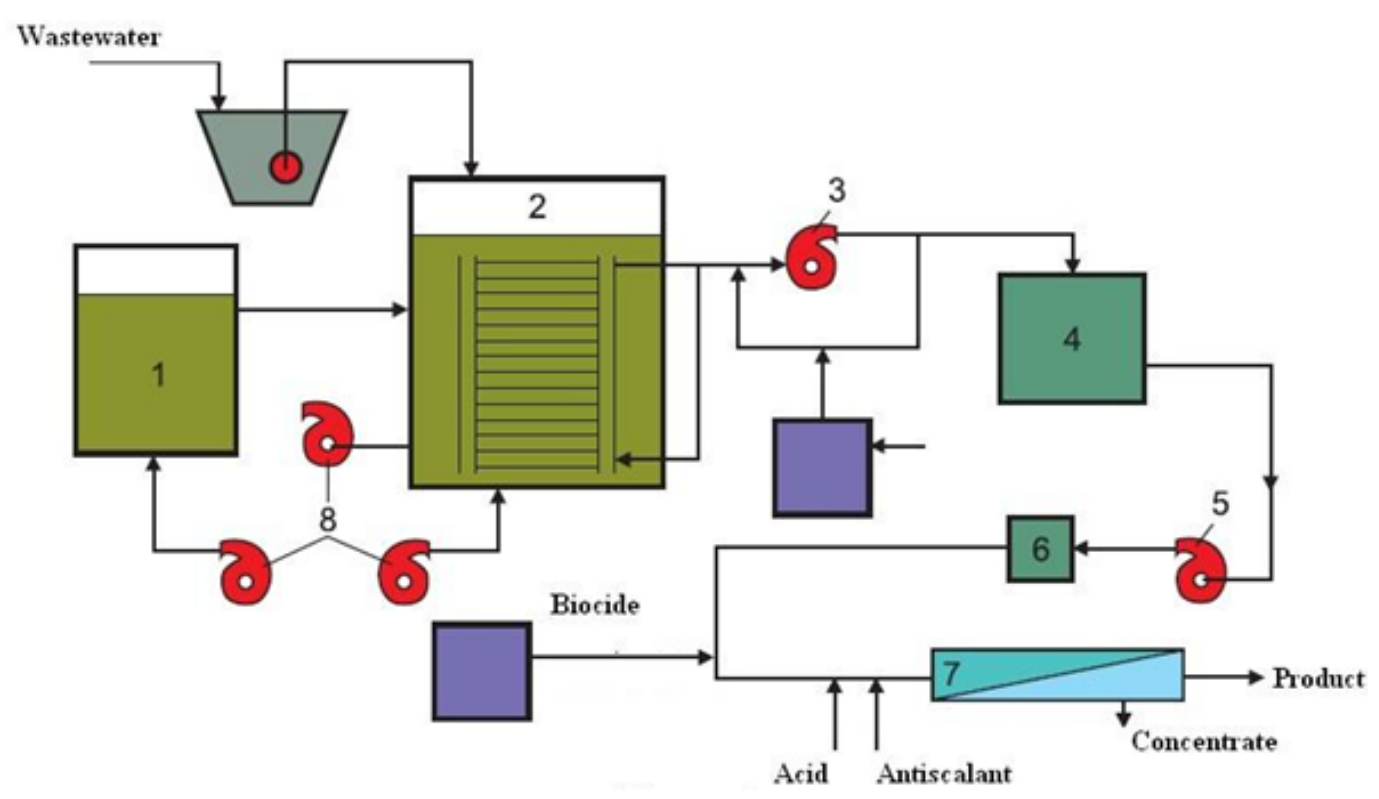

Figure 2. 1 -activated sludge tank, 2 - membrane bioreactor, 3 -vacuum-pump, 4 -product tank, 5 - high pressure pump, 6 - cartridge filter, 7 - reverse osmosis module, 8 -air pumps.

Ultrafiltration submersed membranes (membrane cassettes tailored with flatsheet or capillary membranes) are used for adequate pretreatment of biologically treated wastewater. Product water 
is collected in the tank for further RO desalination, acid and antiscalant solutions are injected in feedwater tank to control scaling in membrane modules.

Meanwhile, high rejection characteristics of RO membranes enable us to treat sewage directly and obtain high-quality water without application of biological processes. This approach to using membrane tools substantially reduces costs and simplifies treatment techniques. However, the main disadvantages of commercially available RO facilities are attributed to high fouling propensities, high cost pretreatment requirements, and concentrate disposal problems. To overcome these problems, a series of experimental investigations was performed to develop newly modified "open channel" modules that possess a limited scaling and fouling potential. As was presented in a number of publications [3], elimination of the spacer mesh from the feed channels of a spiral wound membrane configuration eliminates "dead regions" that provide scaling (crystal formation) and fouling conditions while also reducing the risk of particle "trapping" and the increase of associated dramatic flow resistance. Fouling control is achieved by providing sufficient cross-flow velocities, flushing, and cleanings. RO membrane units can thus be used to efficiently treat wastewater and reuse it for technical and irrigation purposes. In a number of cases such as private housing and small enterprises it's reasonably possible to reduce tap water consumption and domestic water discharge in municipal sewer.

A new concept of direct wastewater treatment by $\mathrm{RO}$ is based on the following principles: - using of membrane modules with an "open channel" enables us to avoid membrane fouling throughout their operation even with high suspended matter content in the feed water; - membrane units are operated in the circulation mode with high cross flow velocities that provide the "shear effect" of adhered foulants; fouling control is achieved by providing sufficient cross flow velocities, flushings and cleanings;

-foulants accumulated on membrane surface are withdrawn from membrane module during membrane flushes. Suspended matter after membrane flushes is collected, sedimented and finally dewatered.

-the main principles of high recoveries maintenance are ensured by concentration of feedwater in circulation mode by 50-100 times by volume. Concentrate volume constitutes no more than 0,5 -1 $\%$ of the initial feed water volume and is withdrawn from the system together with a wet sludge as a sludge humidity.

Membrane treatment efficiencies to remove oil products, detergents, to reduce BOD and TDS under described RO operation conditions (with concentrate volume decreased by 99\%) were investigated. Tables 1 and 2 show membrane treatment efficiencies in separating storm water and car wash effluent depending on product recovery values. A test program was undertaken to investigate rejection of membranes versus recovery values. A flow diagram of the test unit is shown on figure 3. 
a)

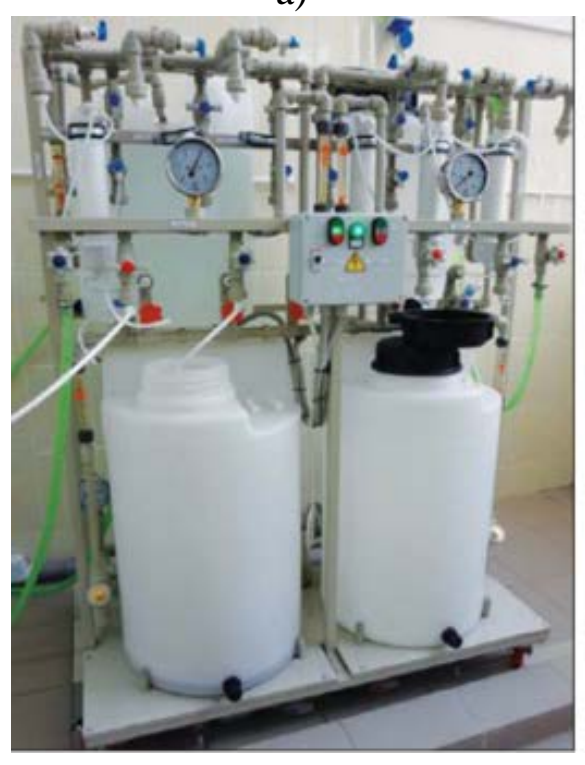

b)

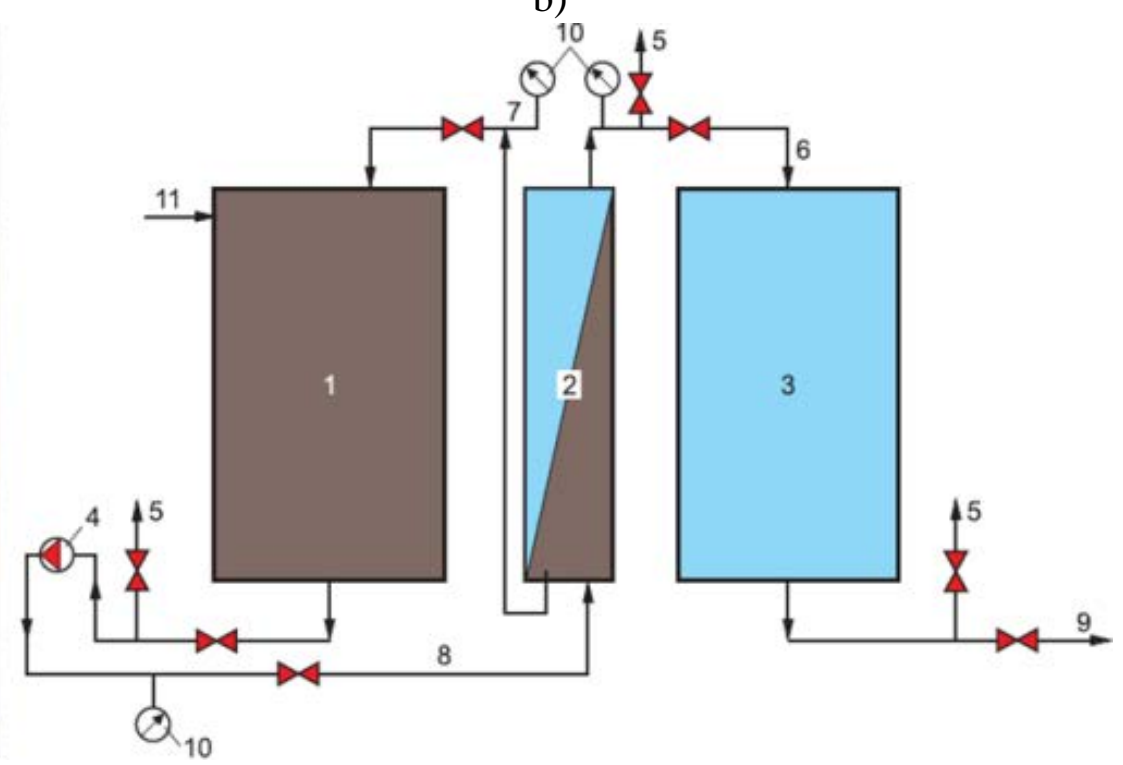

Figure 3. $(a, b)$ Double stage RO membrane unit for laboratory tests: $a$ - photo; $b$ - flow diagram. 1 - feed water tank; 2 - membrane module; 3 - product water tank; 4 - pressure pump; 5 - tap of sampling; 6 - product water; 7 - RO concentrate; 8 -feed water; 9 - product water; 10 manometer

Table 1. Concentration values of different water, product and concentrate throughout stormwater treatment.

\begin{tabular}{|c|c|c|c|c|c|c|c|}
\hline & Normal & $\begin{array}{l}\text { Feed } \\
\text { wastewater }\end{array}$ & $\begin{array}{l}\text { Average } \\
\text { RO } \\
\text { product }\end{array}$ & $\begin{array}{l}\text { Second RO } \\
\text { stage product }\end{array}$ & $\begin{array}{l}\text { Second } \\
\text { RO } \\
\text { concentrate }\end{array}$ & $\mathrm{P} \times 90$ & $\mathrm{C} \times 90$ \\
\hline $\begin{array}{l}\text { Suspended } \\
\text { solids mg/L }\end{array}$ & 3 & 23,8 & 0,39 & 0,29 & 34,0 & 3,4 & 119 \\
\hline $\mathrm{BOD}, \mathrm{mg} / \mathrm{L}$ & 3 & 7,24 & 4,7 & 4,0 & 177,0 & 43,8 & 784 \\
\hline $\mathrm{Cl}, \mathrm{mg} / \mathrm{L}$ & - & 266,0 & - & - & 568,0 & 795 & 5822 \\
\hline $\mathrm{Fe}, \mathrm{mg} / \mathrm{L}$ & 0,1 & 1,72 & 0,106 & 0,169 & 2,3 & 0,044 & 6,2 \\
\hline Oil, mg/L & 0,05 & 0,55 & $<0,01$ & 0,06 & 1,27 & 0,188 & 10,1 \\
\hline TOC, mg/L & - & 0,494 & 0,046 & 0,232 & 0,292 & 0,054 & 1,86 \\
\hline TDS, mg/L & 1000 & 465 & 363 & 50 & 1280 & 2700 & 12150 \\
\hline
\end{tabular}

Table 2. Concentration of oil, detergents, $B O D$ in product water and concentrate of RO system during car wash treatment

\begin{tabular}{llllllll}
\hline & $\begin{array}{l}\text { Feed waste } \\
\text { water }\end{array}$ & $\begin{array}{l}\text { Average } \\
\text { product }\end{array}$ & RO & $\begin{array}{l}\text { First } \\
\text { stage product }\end{array}$ & $\begin{array}{l}\text { First } \\
\text { RO } \\
\text { concentrate }\end{array}$ & P x20 & C x20 \\
\hline $\begin{array}{l}\text { Suspended } \\
\text { solids mg/L }\end{array}$ & 49,6 & $<0,10$ & $<0,10$ & 80,2 & $<0,10$ & 186,0 \\
\hline
\end{tabular}


Linnaeus ECO-TECH '14,

Kalmar, Sweden, November 24-26, 2014

\begin{tabular}{|c|c|c|c|c|c|c|}
\hline BOD, mg/L & 65,7 & 2,84 & 3,81 & 164,0 & 16,0 & 275,0 \\
\hline Oil, mg/L & 4,19 & 0,081 & $<0,001$ & 6,0 & 0,372 & 13,4 \\
\hline TOC, mg/L & 0,262 & 0,001 & 0,008 & 0,048 & 0,013 & 0,753 \\
\hline TDS, mg/L & 774 & 53,2 & 21 & 972 & 306 & 8910 \\
\hline
\end{tabular}

Figure 4 shows a schematic flow diagram of an RO unit developed for wastewater treatment and reuse in a residential home. Wastewater is taken directly from the sewer; feedwater passes through Miller Pump (mills large size impurities such as paper, etc.), and is then forwarded to the screen that is automatically flushed to remove foulants and direct them back into a drain. Wastewater is then treated by RO membranes. The foulants that are accumulated on membrane surface are periodically removed through application of membrane flushings. The membrane unit is operated in circulation mode that ensures high concentrate flow velocities that provide a "shear" effect to prevent sedimentation of suspended particles on membrane surface and membrane fouling. Product water can be used for technical purposes (plant watering, car washing, heating or cooling systems feed). The use of RO unit provides reuse of $80-90 \%$ of domestic wastewater. Yet, the majority of utilities lack the legal permission to discharge of RO concentrate. To evaluate developed measures to reduce concentrate flow and increase recoveries, a pilot testing program was implemented.

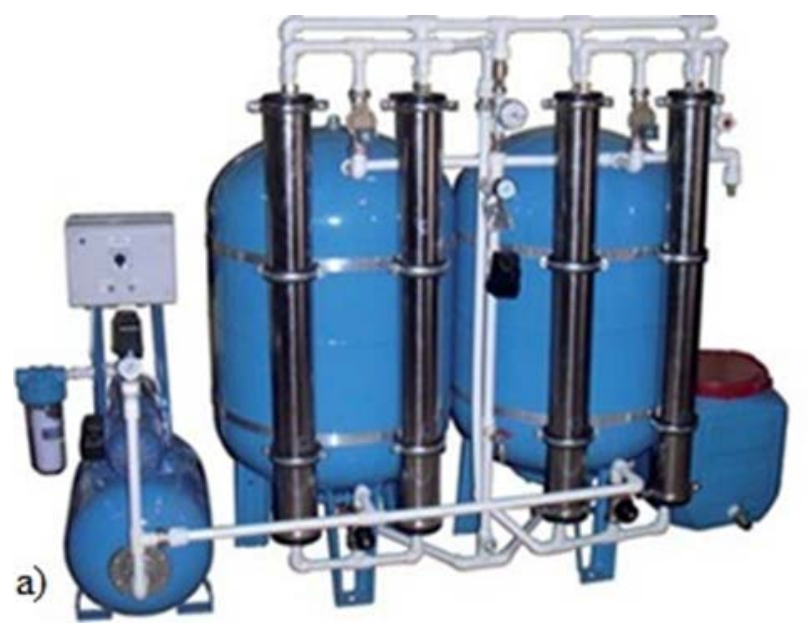

b)

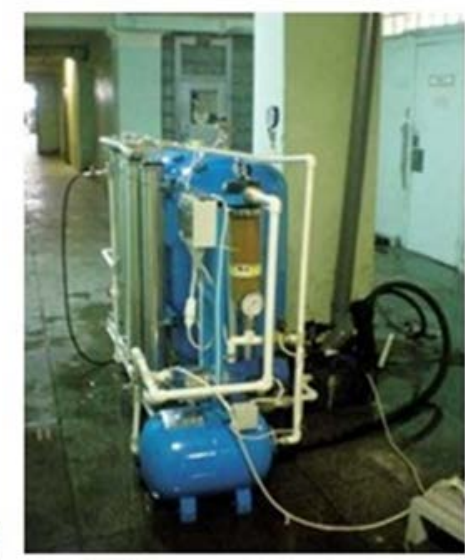




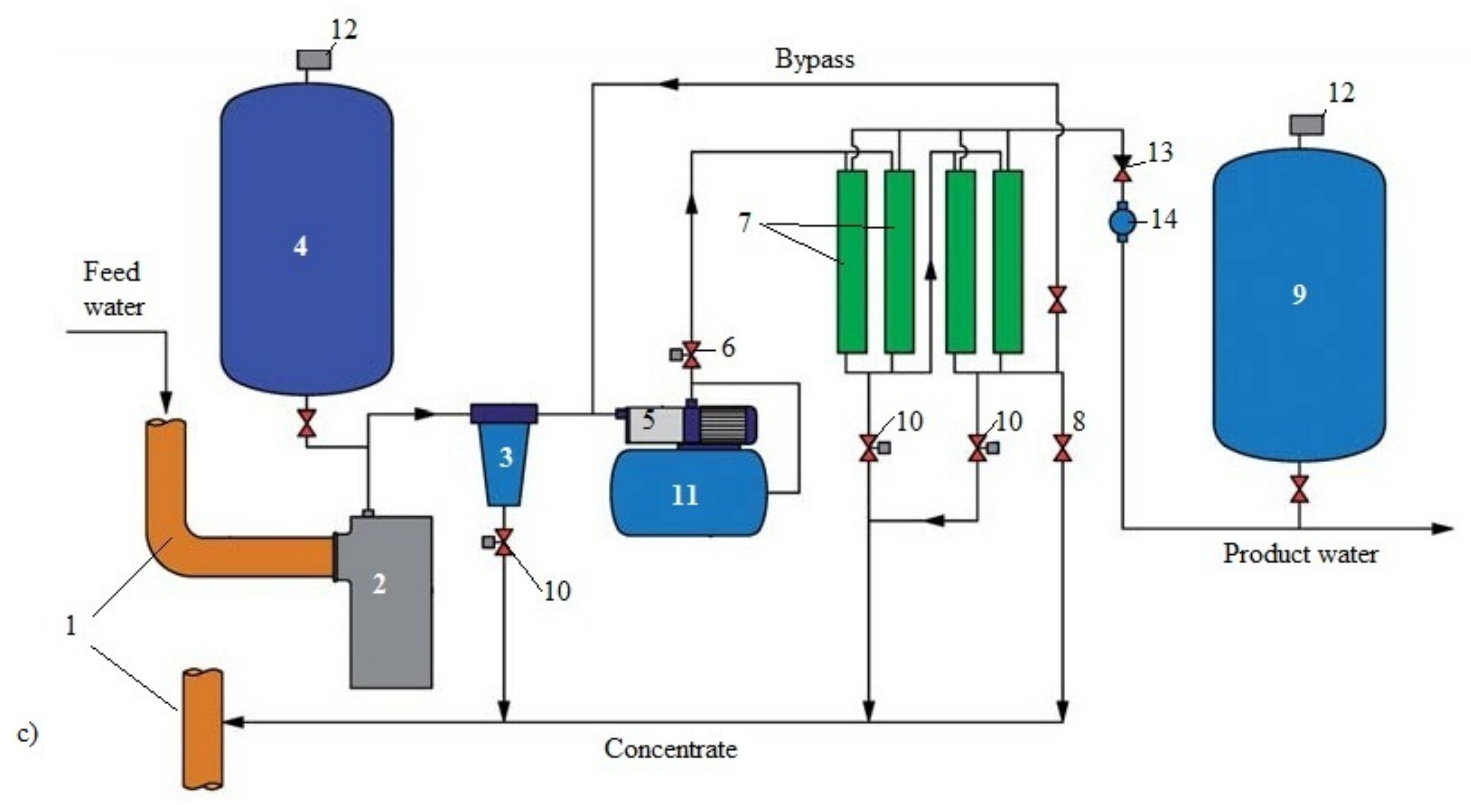

Figure 4. Reverse Osmosis unit to treat municipal wastewater a) pilot testing at the basement of the building; b) general view; c) flow diagram. 1- main sewer; 2- milling pump; 3- backwashed screen mesh; 4- feedwater pressurized tank; 5- pressure pump; 6 - solenoid valve at the inlet; 7 membrane modules; 8- pressure gauge; 9 - product water pressurized tank; 10 - solenoid valves for flushing; 11 - pressurized flushing tank; 12 -pressure relay; 13- check valve; 14- flow counter.

\section{PRINCIPLES OF RATIONAL WATER MANAGEMENT IN LOCAL UTILITES USING DEVELOPED RO TECHNIQES}

The modern concept of rational water resources management requires the development of new and efficient techniques for the treatment and reuse of wastewater. The author developed an approach to solve the problem of environmental pollution.

This approach results in the development of local water management programs. The efficiency of the RO techniques depends on wastewater salinity. The data presented in figure 5 indicate that the efficiency of RO (the possibility of reducing concentrate flow to $1 \%$ ) is dependent on the feed water TDS. To reduce wastewater TDS, RO membrane units should be used to produce potable water (that ultimately goes to the sewer) and to produce boiler feed water for heating systems (replacing ion exchange softeners conventionally used for water softening) to avoid discharge of regeneration solutions to the sewer. The purified wastewater can be used for garden irrigation, washing cars, and to feed cooling/heating systems. Storm water that contains oil and surfactants is also purified by similar RO techniques. This treatment and concentrate utilization is facilitated by low TDS of storm water. 


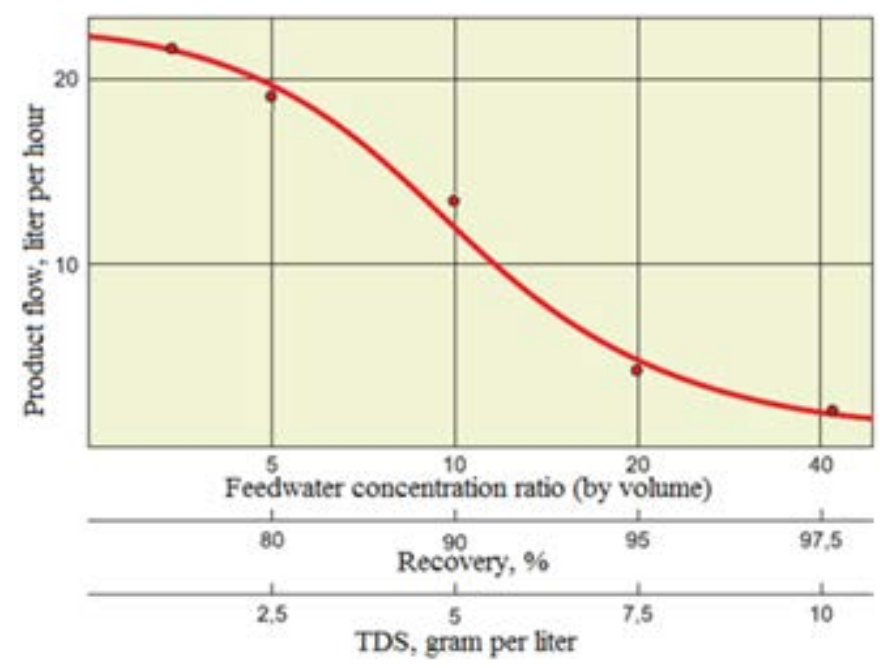

Figure 5. Reduction of product flow with TDS growth during storm water treatment by double stage $R O$.

To decrease groundwater consumption and wastewater discharge, wastewater effluents can be treated by a local RO plant to provide quality technical water that can be reused for boiler feed, car washing, plant watering. To reduce concentrate flow value, membrane RO units should be also used for drinking water production. Membrane units produce water with decreased TDS, iron and hardness concentrations. Therefore, total TDS of wastewater can be significantly reduced through the use of RO, and concentrate discharge could be minimized. With the average unit water consumption value assumed at 200-250 liter per person daily, wastewater after shower and toilet use increased TDS by only 40-50 ppm. If supplied water has TDS value of $100 \mathrm{ppm}$ or less, this water could be easily treated by RO and RO concentrate could be easily utilized and discharged as sludge humidity. Figure 6 and 7 shows water flow distribution: a flow diagram of water supply and wastewater treatment facilities developed for a small utility of 200-300 residents.

There is no place to discharge wastewater, and the suggested techniques enable to completely reuse it for local industrial needs such as: boiler feed, heating, cooling, plant watering.

Membrane facilities tailored with "open channel" modules can be used for multi-purpose needs as they can treat wastewater and well water. Thus, local water utilities can use the same RO unit for technical water production (for boiler feed, heating and cooling) using both well water source and collected storm water.

This provides an efficient return of investment in storm water treatment and reuse.

A strategy of local utilities water management is developed that is based on the use of membrane facilities both for water supply and wastewater treatment/reuse. Membrane units provide efficient product water quality when treating both municipal and storm water to purify and reuse it for technical purposes: for boiler feed and heating, for cooling systems and garden pouring.

To reduce the amount of wet sludge discharge, wastewater ionic composition should also be controlled using RO to produce low TDS product water for drinking and domestic needs. 
To facilitate treatment of wastewater, small size local membrane units are used at the points where "sources of contamination" are detected: ion exchange regeneration solution discharges, storm water collected from car parking lots, gas stations and gas storage tanks.
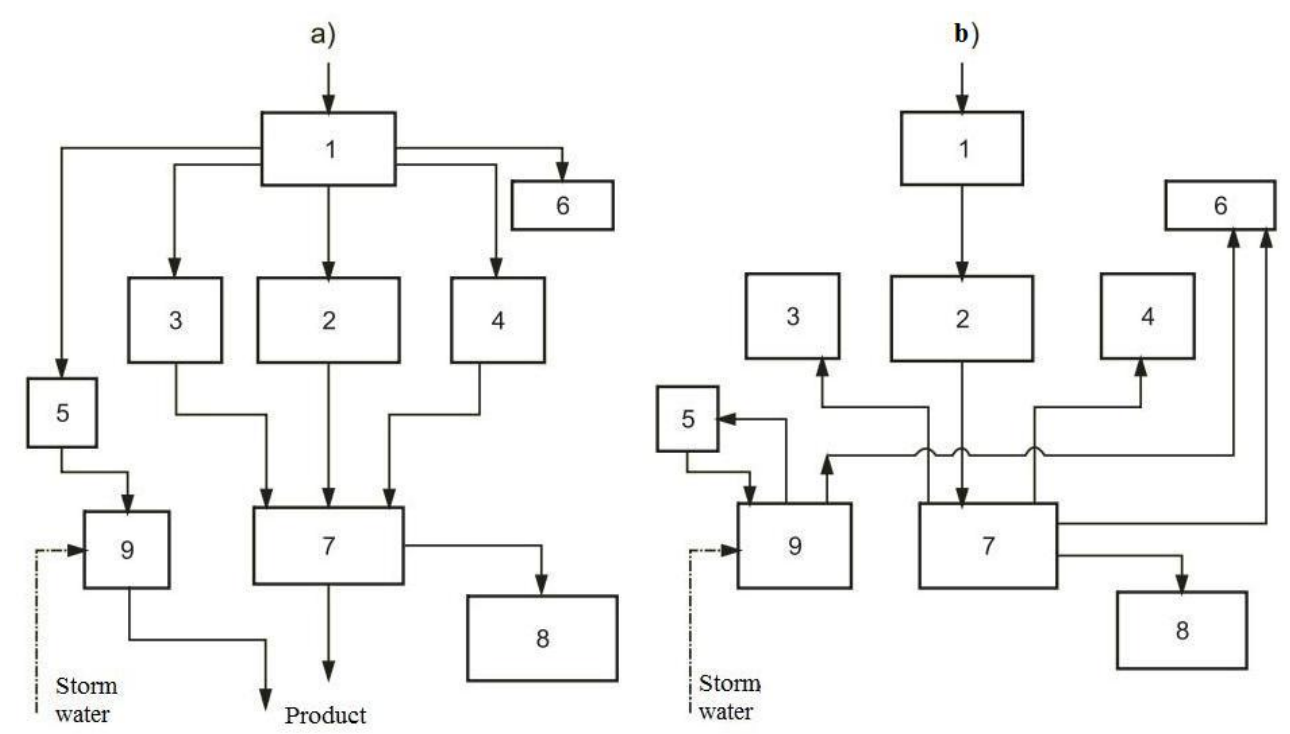

Figure 6. A balance flow diagrams of water supply and wastewater treatment at a local utility: existing scheme (a) and proposed scheme using membrane techniques (b). 1- water treatment plant ( $a$ - iron removal; $b$-RO plant); 2 - facilities buildings; 3 - compressor pump station; 4 - boilers; 5 - car washing ground; 6 - plant watering station; 7 - wastewater treatment plant; 8 - sludge beds ; 9 - storm water treatment and car washing effluents treatment station

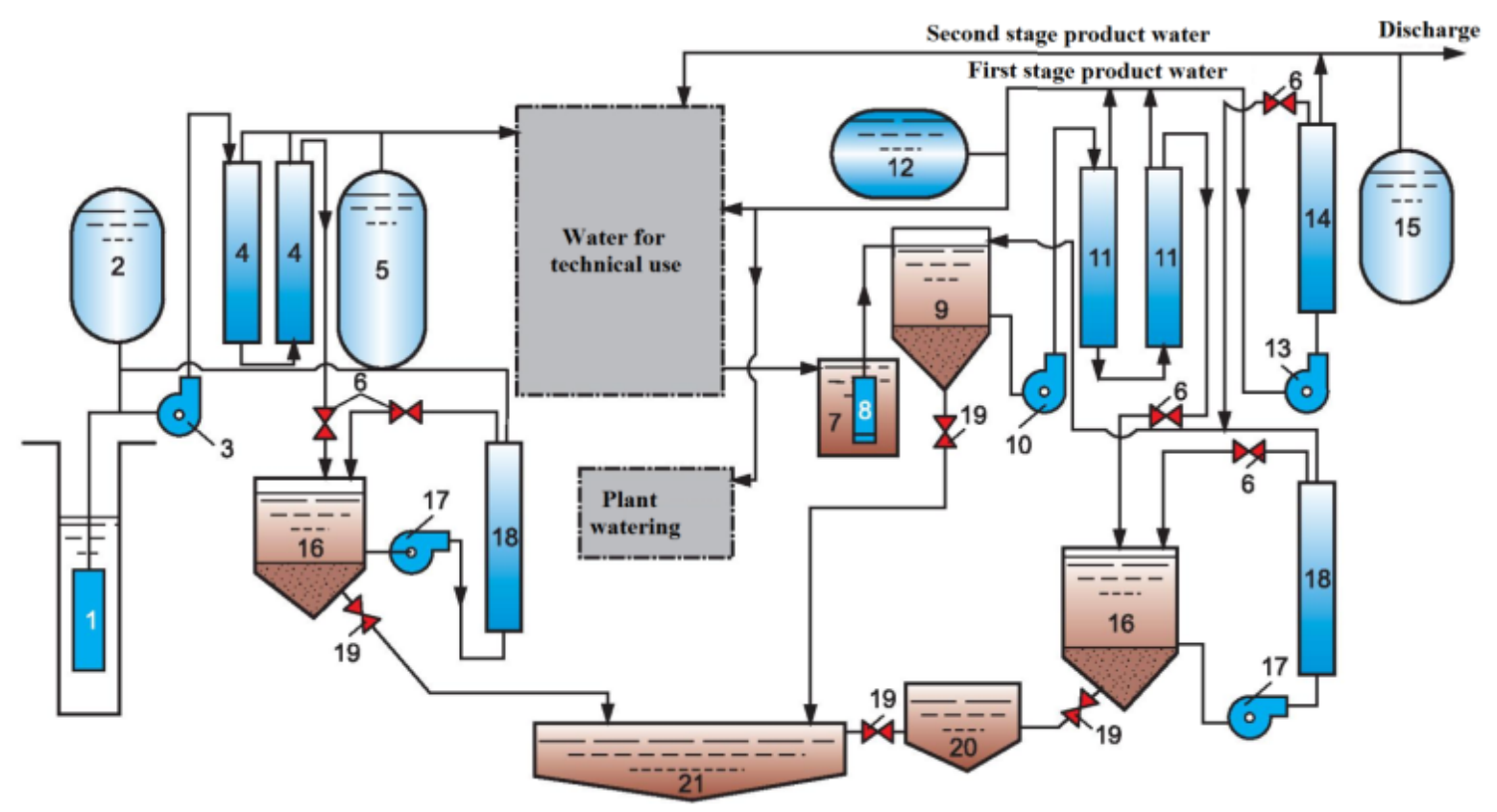

Figure 7. Flow diagram of membrane techniques used for drinking water production, wastewater treatment and reuse. 1 - well pump; 2 - well water pressure tank; 3 - membrane unit pump; 4 - 
membrane modules; 5 - product water pressure tank; 6 - pressure gauges; 7 -wastewater collection tank; 8 - wastewater feed pump; 9 - first stage RO concentrate sedimentation tank; 10 - first stage RO pressure pump; 11 - first stage RO membrane modules; 12 - first stage RO pressure tank; 13 - second stage RO pump; 14 - second stage RO membrane modules; 15 second stage RO pressure tank; 16 - second stage RO concentrate sedimentation tank; 17 concentrate flow reduction unit pump; 18 - concentrate flow reduction unit membrane module; 19 - sludge disposal valve; 20 - septic tank; 21 - sludge bed.

\section{STORMWATER TREATMENT}

The use of local membrane systems can radically change a concept of storm water treatment. All storm water collected after rainfall should not be treated for oil and detergent removal. Storm water can be collected and treated by RO in the "sources" of contamination, such as gas stations, parking lots, oil and gas storage tanks. For most storm water, conventional sedimentation and filtration facilities can be used that do not have high operational costs.

Storm water is treated by a double stage RO membrane unit [4], shown on figure 9. Concentrate flow is decreased by 50 - 100 times and is withdrawn from the system together with wet sludge as a sludge moisture. At car washes, an equilibrium is reached between the amount of salt that enters the system with cleaning water and the amount of salt that is contained in the sludge that is removed from the system. To determine required membrane characteristics and optimum operational parameters, a test program was undertaken.

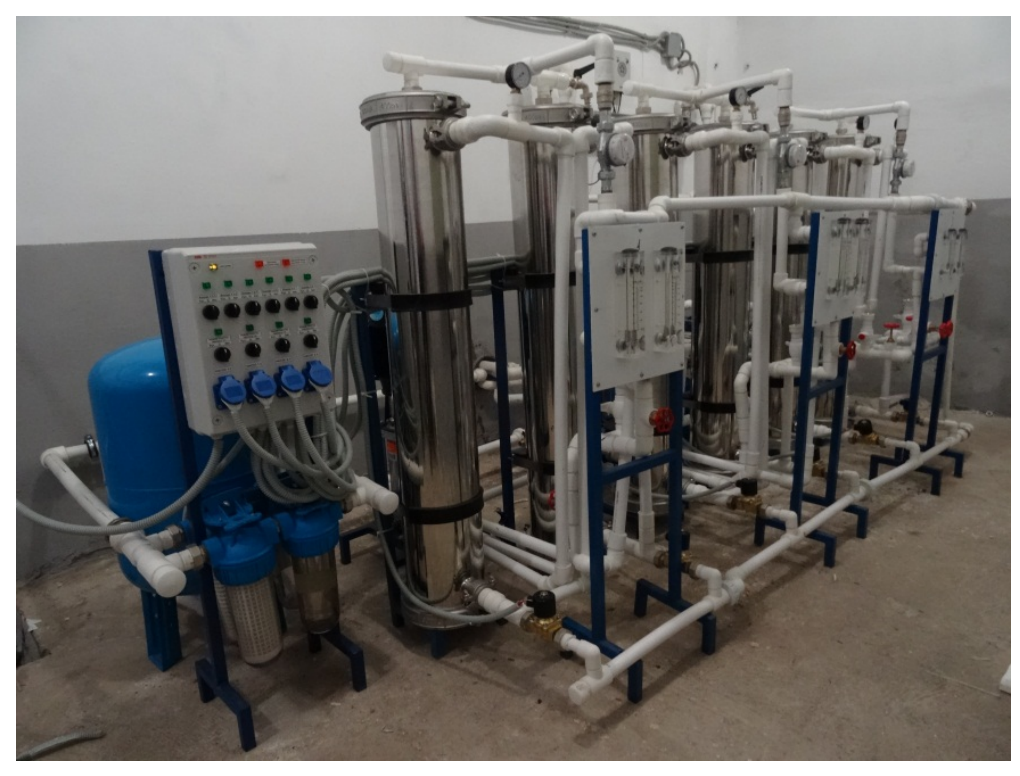

Figure 8. Double stage RO membrane unit for wastewater treatment, 6,5 cubic meter per hour capacity: operation of the membrane unit at local storm water treatment facilities (FSUE TSENKI, Moscow, Russia). 
Linnaeus ECO-TECH '14,

Kalmar, Sweden, November 24-26, 2014

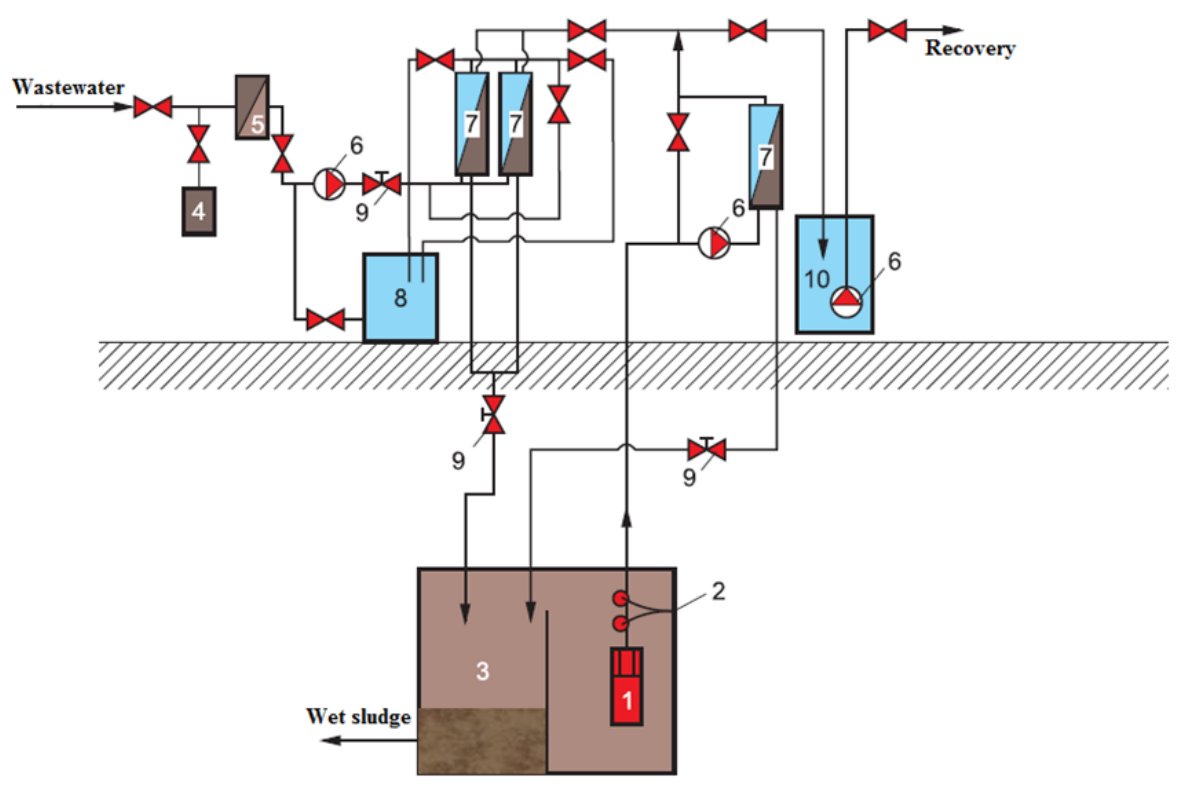

Figure 9. Schematic flow diagram of storm water treatment: 1 -wastewater well pump; 2 - float switch; 3 -sedimentation tank; 4 -accumulation tank; 5 - pretreatment screen; 6 -pressure pump; 7 - membrane modules; 8- cleaning tank; solenoid valve; 9 - product water tank. 


\section{CONCLUSIONS}

Long research devoted to membrane fouling has revealed that fouling mechanisms depend not only on hydrodynamic conditions in membrane channel, but on membrane material sorption characteristics and channel configuration as well. The existing spiral wound modules used in RO, NF and UF facilities are very susceptible to fouling that makes them useless for water treatment containing high organics, bacteria and suspended matter.

Main disadvantages of spiral wound modules are attributed to presence of spacer mesh in the channel that trap fouling particles and increase delta-pressure of the module.

Introduction of new open-channel modules suggests a new approach to treat wastewater with high fouling potential without a fear to suffer fouling problems throughout a long period of stable operation.

The main principles of high recovery maintenance are ensured by concentration of the feed water in circulation mode by 50-100 times by volume. Concentrate volume constitutes no more than $0,5-$ $1 \%$ of the initial feed water volume and is withdrawn from the system together with a wet sludge as a sludge moisture.

The paper demonstrates the design of "integrated" water management using the developed RO systems for water supply and wastewater reuse as an example of advanced, ecologically-safe water treatment. Local utilities and privately-held industrial sites are encouraged to reuse wastewater and reduce freshwater intake, thereby promoting rational water management and reducing environmental pollution.

\section{REFERENCES}

[1] Riddle, Open channel ultrafiltration for reverse osmosis pretreatment, IDA world conference on Desalination and Water reuse August 25-29, 1991, Washington. Pretreatment and fouling.

[2] A. Pervov, A. Melnikov, The determination of the required foulant removal degree in RO feed pretreatment, IDA world conference on Desalination and Water reuse August 25-29, 1991, Washington. Pretreatment and fouling.

[3] A. Andrianov, A. Pervov, D. Spitsov, Treatment of natural water with UF and NF membranes: new ways to reduce fouling, Proc. of IWA Regional conference - Membrane technologies in water and waste water treatment, June $2-4$, 2008, Moscow, Russia, 476482.

[4] N. Matveev, A. Pervov. Use of reverse osmosis to treat domestic wastewater for local utilities and in small industries. Tianjin IDA world congress 2013 on desalination and water reuse. IDAWC REF: TIAN13-217. 20-25 October, China, 2013. 